\title{
Quadrupole Hyperfine Structure in the Rotational Spectra of Sulfur Dichloride
}

\author{
Ilona Merke and Helmut Dreizler \\ Abteilung Chemische Physik im Institut für Physikalische Chemie der Universität Kiel, Kiel, FRG
}

Z. Naturforsch. 47 a, $1141-1144$ (1992); received August 26, 1992

\begin{abstract}
The nuclear quadrupole coupling of $\left[{ }^{35} \mathrm{Cl},{ }^{35} \mathrm{Cl}\right]$ - and $\left[{ }^{35} \mathrm{Cl},{ }^{37} \mathrm{Cl}\right]$-sulfur dichloride was investigated using waveguide microwave Fourier transform (MWFT) spectroscopy. The analysis was performed with direct diagonalization of the Hamilton matrix. Due to some measured transitions with near degeneracy it was possible to determine the off diagonal elements $\chi_{a b}$ of the quadrupole coupling tensor with high accuracy.

$\mathrm{S}^{35} \mathrm{Cl}_{2}: \chi_{a a}\left({ }^{35} \mathrm{Cl} 1\right)=\chi_{a a}\left({ }^{35} \mathrm{Cl} 2\right)=-38.671(11) \mathrm{MHz}, \quad \chi_{c c}\left({ }^{35} \mathrm{Cl} 1\right)=\chi_{c c}\left({ }^{35} \mathrm{Cl} 2\right)=47.7945(66) \mathrm{MHz}$, $\chi_{a b}\left({ }^{35} \mathrm{Cl} 1\right)=-\chi_{a b}\left({ }^{35} \mathrm{Cl} 2\right)= \pm 53.76(23) \mathrm{MHz}$.

$\mathrm{S}^{35} \mathrm{Cl}^{36} \mathrm{Cl}: \quad \chi_{a a}\left({ }^{35} \mathrm{Cl}\right)=-37.756(13) \mathrm{MHz}, \quad \chi_{c c}\left({ }^{35} \mathrm{Cl}\right)=47.7915(75) \mathrm{MHz}$,

$$
\chi_{a b}\left({ }^{35} \mathrm{Cl}\right)= \pm 54.018(83) \mathrm{MHz}, \quad \chi_{a a}\left({ }^{35} \mathrm{Cl}\right)=-31.217(13) \mathrm{MHz},
$$$$
\chi_{c c}\left({ }^{37} \mathrm{Cl}\right)=37.6759(66) \mathrm{MHz}, \quad \chi_{a b}\left({ }^{37} \mathrm{Cl}\right)=\mp 42.285(98) \mathrm{MHz} .
$$

We also determined the quadrupole coupling constants in their principal axes system. In comparison with the $r_{\mathrm{s}}$-structure the $z$-axis of the coupling tensor was found to be tilted $1.3^{\circ}$ out of the $\mathrm{S}-\mathrm{Cl}$ bond axis.

\section{Introduction}

Microwave investigations of $\mathrm{SCl}_{2}$ were first performed by Murray et al. [1] in 1972. They determined the $r_{0}$-structure, the dipole moment, and the chlorine quadrupole coupling of the most abundant isotopomer. With further investigations and analyses with second order perturbation theory Murray et al. [2] were able to determine the off diagonal element of the coupling tensor $\chi_{a b}= \pm 64(10) \mathrm{MHz}$. The $\mathrm{S}-\mathrm{Cl}$ bond axis was assumed to be a principal axis of the field gradient tensor. In 1977 Davis et al. [3] investigated the spectrum of $\mathrm{S}^{35} \mathrm{Cl}_{2}$ in the vibrational ground and first excited $\left(v_{2}=1\right)$ state and $\mathrm{S}^{35} \mathrm{Cl}^{37} \mathrm{Cl}$ in the vibrational ground state. They evaluated a particular $r_{\mathrm{s}}$-structure, centrifugal distortion constants, and the quartic potential function as well as an averaged structure of the $\left(\begin{array}{lll}0 & 0 & 0\end{array}\right)$ and $\left(\begin{array}{lll}0 & 1 & 0\end{array}\right)$ levels.

In this work the spectra of $\mathrm{S}^{35} \mathrm{Cl}_{2}$ and $\mathrm{S}^{35} \mathrm{Cl}^{37} \mathrm{Cl}$ were recorded with high resolution. We improved the values of the coupling constants of $\mathrm{S}^{35} \mathrm{Cl}_{2}$ and $\mathrm{S}^{35} \mathrm{Cl}^{37} \mathrm{Cl}$ and determined the off diagonal elements $\chi_{a b}$. The knowledge of the complete coupling tensor enabled us to determine the orientation of the cou-

Reprint requests to Prof. Dr. H. Dreizler, Abteilung Chemische Physik, Institut für Physikalische Chemie, Universität Kiel, Olshausenstr. 40-60, 2300 Kiel 1, FRG. pling tensor and its principal coupling elements without further assumptions. Using the molecular structure [3] it is possible to get experimental information on the possibility of bent bonds.

\section{Experimental}

$\mathrm{SCl}_{2}$ was purchased by Aldrich Chemie, Steinheim. Air and $\mathrm{Cl}_{2}$ were removed by repeated freezing and melting the substance in vacuum. The substance was then used without further purification. During the measurements in metal cells rapid decomposition of the substance caused problems, as also mentioned in [2] and [3]. Since $\mathrm{SCl}_{2}$ is in equilibrium with $\mathrm{S}_{2} \mathrm{Cl}_{2}$

$$
2 \mathrm{SCl}_{2} \rightleftharpoons \mathrm{S}_{2} \mathrm{Cl}+\mathrm{Cl}_{2}
$$

and $\mathrm{Cl}_{2}$ reacts with the walls of the cell the reaction favors to go to the right hand side. The substance reacts fast with copper cells, slower with brass cells.

The measurements were performed with waveguide-MWFT-spectrometers in the frequency range from 4 to $40 \mathrm{GHz}$ [4-6] with a flow system in a pressure range of 0.1 to $0.3 \mathrm{~Pa}$ ( 1 to $2 \mathrm{mTorr}$ ) and temperatures around $243 \mathrm{~K}$.

In order to eliminate overlap effects [7] the frequencies were determined by a least squares fit to the molecular time domain signal [8]. A list of some se- 
Table 1. Selected rotational transitions of sulfur dichloride. $v$ : measured frequency [MHz], $\delta_{\mathrm{hfs}}$ : observed-minus-calculated frequency of the hyperfine component $[\mathrm{kHz}] . v_{0}$ : hypothetical center frequency $[\mathrm{MHz}]$.

Table $1 \mathrm{a}: \mathrm{S}^{35} \mathrm{Cl}_{2}$.

\begin{tabular}{|c|c|c|c|c|}
\hline $\begin{array}{c}J^{\prime} K_{a}^{\prime} K_{c}^{\prime}-J K_{a} K_{c} \\
v_{0} \\
\end{array}$ & $I^{\prime} F^{\prime}$ & $I F$ & $v$ & $\delta_{\mathrm{hfs}}$ \\
\hline $\begin{array}{llllll}3 & 0 & 3 & -2 & 1 & 2 \\
4 & 776.6610 & (15)\end{array}$ & $\begin{array}{ll}3 & 5 \\
1 & 2 \\
3 & 4 \\
3 & 6 \\
1 & 4 \\
3 & 4 \\
1 & 3 \\
3 & 1 \\
3 & 3 \\
1 & 2 \\
3 & 2 \\
3 & 3 \\
3 & 2 \\
3 & 5\end{array}$ & $\begin{array}{ll}3 & 4 \\
1 & 1 \\
3 & 3 \\
3 & 5 \\
1 & 3 \\
3 & 4 \\
1 & 2 \\
3 & 1 \\
3 & 2 \\
3 & 2 \\
1 & 2 \\
1 & 3 \\
3 & 1 \\
3 & 5\end{array}$ & $\begin{array}{l}4779.983 \\
4779.011 \\
4777.837 \\
4776.766 \\
4774.773 \\
4774.412 \\
4773.918 \\
4772.604 \\
4771.360 \\
4769.193 \\
4769.138 \\
4767.951 \\
4766.163 \\
4762.923\end{array}$ & $\begin{array}{r}3.0 \\
0.1 \\
1.1 \\
3.8 \\
1.4 \\
-3.3 \\
1.4 \\
-1.8 \\
0.9 \\
2.1 \\
-3.3 \\
-10.3 \\
5.3 \\
-0.4\end{array}$ \\
\hline 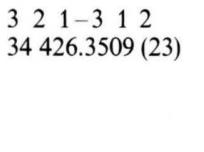 & $\begin{array}{ll}3 & 4 \\
3 & 5 \\
1 & 4 \\
3 & 6 \\
1 & 3\end{array}$ & $\begin{array}{ll}3 & 4 \\
3 & 5 \\
1 & 4 \\
3 & 6 \\
1 & 3\end{array}$ & $\begin{array}{l}34427.504 \\
34427.005 \\
34426.293 \\
34425.770 \\
34425.391\end{array}$ & $\begin{array}{r}-4.0 \\
-3.3 \\
-0.1 \\
5.3 \\
1.9\end{array}$ \\
\hline 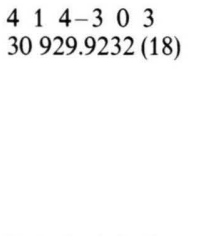 & $\begin{array}{ll}1 & 4 \\
3 & 7 \\
1 & 5 \\
3 & 3 \\
3 & 6 \\
1 & 3 \\
3 & 4 \\
3 & 5\end{array}$ & $\begin{array}{ll}1 & 3 \\
3 & 6 \\
1 & 4 \\
3 & 2 \\
3 & 5 \\
1 & 2 \\
3 & 3 \\
3 & 4\end{array}$ & $\begin{array}{l}30934.918 \\
30934.314 \\
30929.856 \\
30928.558 \\
30928.367 \\
30926.106 \\
30924.127 \\
30923.580\end{array}$ & $\begin{array}{r}14.8 \\
1.5 \\
-1.1 \\
-5.5 \\
1.7 \\
-9.3 \\
-0.3 \\
-1.4\end{array}$ \\
\hline 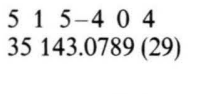 & $\begin{array}{ll}2 & 5 \\
2 & 7 \\
0 & 5\end{array}$ & $\begin{array}{ll}2 & 4 \\
2 & 6 \\
0 & 4\end{array}$ & $\begin{array}{l}35148.291 \\
35143.059 \\
35137.800\end{array}$ & $\begin{array}{r}-1.2 \\
2.7 \\
-1.4\end{array}$ \\
\hline $\begin{array}{llllll}5 & 1 & 4 & -5 & 0 & 5 \\
16 & 027.0963 & (17)\end{array}$ & $\begin{array}{ll}3 & 6 \\
3 & 5 \\
1 & 4 \\
3 & 7 \\
1 & 6 \\
3 & 4 \\
3 & 3 \\
3 & 8 \\
1 & 5\end{array}$ & $\begin{array}{ll}3 & 6 \\
3 & 5 \\
1 & 4 \\
3 & 7 \\
1 & 6 \\
3 & 4 \\
3 & 3 \\
3 & 8 \\
1 & 5\end{array}$ & 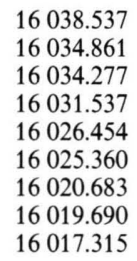 & $\begin{array}{r}-0.4 \\
-12.2 \\
2.4 \\
-3.1 \\
-8.3 \\
19.6 \\
-0.4 \\
-0.2 \\
3.0\end{array}$ \\
\hline $\begin{array}{llllll}5 & 2 & 3 & -5 & 1 & 4 \\
32 & 724.0350 & (18)\end{array}$ & $\begin{array}{ll}3 & 2 \\
1 & 5 \\
3 & 8 \\
3 & 3 \\
3 & 4 \\
1 & 6 \\
3 & 7 \\
1 & 4 \\
3 & 5 \\
3 & 6\end{array}$ & $\begin{array}{ll}3 & 2 \\
1 & 5 \\
3 & 8 \\
3 & 3 \\
3 & 4 \\
1 & 6 \\
3 & 7 \\
1 & 4 \\
3 & 5 \\
3 & 6\end{array}$ & $\begin{array}{l}32726.740 \\
32726.013 \\
32725.413 \\
32725.368 \\
32724.401 \\
32723.860 \\
32723.081 \\
32722.322 \\
32722.296 \\
32721.658\end{array}$ & $\begin{array}{r}-3.1 \\
0.9 \\
0.4 \\
-5.4 \\
-1.1 \\
-0.2 \\
1.4 \\
0.2 \\
2.7 \\
4.2\end{array}$ \\
\hline $\begin{array}{llllll}6 & 2 & 4-6 & 1 & 5 \\
31 & 828.1581 & (21)\end{array}$ & $\begin{array}{ll}0 & 6 \\
2 & 7 \\
2 & 5 \\
2 & 4 \\
2 & 8 \\
2 & 6\end{array}$ & $\begin{array}{ll}2 & 6 \\
2 & 7 \\
2 & 5 \\
2 & 4 \\
2 & 8 \\
0 & 6\end{array}$ & $\begin{array}{ll}31 & 830.066 \\
31 & 828.526 \\
31 & 828.290 \\
31 & 828.205 \\
31 & 827.966 \\
31 & 826.187\end{array}$ & $\begin{array}{r}-1.7 \\
3.4 \\
-1.6 \\
0.3 \\
0.1 \\
-0.3\end{array}$ \\
\hline 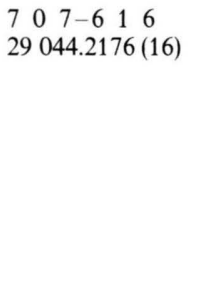 & $\begin{array}{ll}3 & 8 \\
3 & 7 \\
1 & 6 \\
3 & 9 \\
1 & 8 \\
3 & 6 \\
3 & 10 \\
3 & 5 \\
1 & 7 \\
3 & 4\end{array}$ & $\begin{array}{ll}3 & 7 \\
3 & 6 \\
1 & 5 \\
3 & 8 \\
1 & 7 \\
3 & 5 \\
3 & 9 \\
3 & 4 \\
1 & 6 \\
3 & 3\end{array}$ & $\begin{array}{ll}29 & 048.435 \\
29 & 046.687 \\
29 & 046.509 \\
29 & 046.193 \\
29 & 043.902 \\
29 & 043.346 \\
29 & 041.829 \\
29 & 041.260 \\
29 & 040.790 \\
29 & 039.398\end{array}$ & $\begin{array}{r}1.8 \\
-0.0 \\
-0.4 \\
1.0 \\
-2.7 \\
1.2 \\
0.7 \\
-1.2 \\
0.6 \\
-1.4\end{array}$ \\
\hline
\end{tabular}

b) Table 1 b: $\mathrm{S}^{35} \mathrm{Cl}^{37} \mathrm{Cl}$

\begin{tabular}{|c|c|c|c|c|}
\hline $\begin{array}{c}J^{\prime} K_{a}^{\prime} K_{c}^{\prime}-J K_{a} K_{c} \\
v_{0}\end{array}$ & $I^{\prime} F^{\prime}$ & $I F$ & $v$ & $\delta_{\mathrm{hfs}}$ \\
\hline 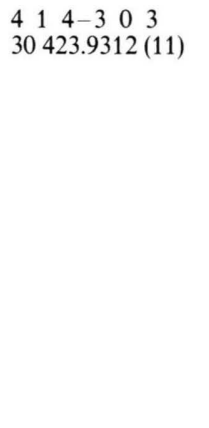 & $\begin{array}{ll}1 & 4 \\
2 & 4 \\
3 & 7 \\
3 & 4 \\
3 & 2 \\
1 & 5 \\
2 & 6 \\
2 & 2 \\
2 & 5 \\
2 & 3 \\
3 & 3 \\
3 & 6 \\
1 & 3 \\
0 & 4 \\
3 & 4 \\
3 & 5\end{array}$ & $\begin{array}{ll}1 & 3 \\
0 & 3 \\
3 & 6 \\
3 & 4 \\
3 & 1 \\
1 & 4 \\
2 & 5 \\
2 & 1 \\
2 & 4 \\
2 & 2 \\
3 & 2 \\
3 & 5 \\
1 & 2 \\
2 & 3 \\
3 & 3 \\
3 & 4\end{array}$ & $\begin{array}{ll}30 & 428.562 \\
30 & 428.336 \\
30 & 427.883 \\
30 & 425.206 \\
30 & 424.749 \\
30 & 424.292 \\
30 & 424.079 \\
30 & 423.703 \\
30 & 423.463 \\
30 & 423.345 \\
30 & 423.277 \\
30 & 422.340 \\
30 & 420.509 \\
30 & 419.207 \\
30 & 418.783 \\
30 & 418.230\end{array}$ & $\begin{array}{r}-0.5 \\
-2.2 \\
7.8 \\
-10.0 \\
-2.6 \\
-0.8 \\
3.4 \\
-4.5 \\
2.5 \\
-0.9 \\
-1.7 \\
5.1 \\
-2.3 \\
-2.6 \\
3.7 \\
4.2\end{array}$ \\
\hline 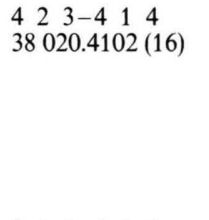 & $\begin{array}{ll}3 & 6 \\
2 & 3 \\
2 & 5 \\
2 & 2 \\
2 & 6 \\
1 & 5 \\
3 & 3 \\
3 & 7\end{array}$ & $\begin{array}{ll}3 & 6 \\
2 & 3 \\
2 & 5 \\
2 & 2 \\
2 & 6 \\
1 & 5 \\
3 & 3 \\
3 & 7\end{array}$ & $\begin{array}{ll}38 & 026.313 \\
38 & 021.020 \\
38 & 020.894 \\
38 & 020.574 \\
38 & 020.181 \\
38 & 018.982 \\
38 & 016.623 \\
38 & 012.875\end{array}$ & $\begin{array}{r}-8.3 \\
13.5 \\
-4.7 \\
-2.8 \\
-5.2 \\
0.2 \\
2.1 \\
6.2\end{array}$ \\
\hline 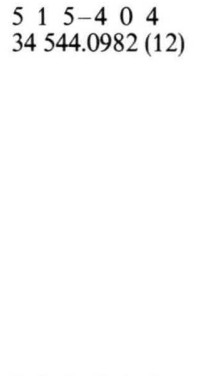 & $\begin{array}{ll}3 & 2 \\
1 & 5 \\
3 & 8 \\
3 & 3 \\
2 & 6 \\
3 & 4 \\
2 & 7 \\
2 & 3 \\
1 & 6 \\
2 & 4 \\
3 & 7 \\
1 & 4 \\
3 & 5 \\
3 & 6\end{array}$ & $\begin{array}{ll}3 & 1 \\
1 & 4 \\
3 & 7 \\
3 & 2 \\
1 & 5 \\
3 & 3 \\
2 & 6 \\
2 & 2 \\
2 & 5 \\
2 & 3 \\
3 & 6 \\
1 & 3 \\
3 & 4 \\
3 & 5\end{array}$ & 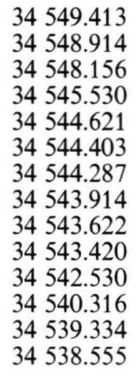 & $\begin{array}{r}-2.7 \\
-1.0 \\
5.0 \\
-5.0 \\
2.7 \\
0.7 \\
3.8 \\
-2.0 \\
3.1 \\
-1.0 \\
4.6 \\
-1.8 \\
-4.3 \\
-1.2\end{array}$ \\
\hline 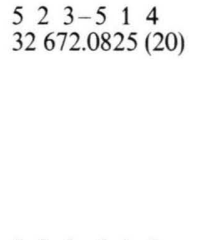 & $\begin{array}{ll}3 & 2 \\
3 & 8 \\
1 & 6 \\
2 & 7 \\
2 & 6 \\
1 & 4 \\
3 & 7 \\
0 & 5 \\
3 & 6\end{array}$ & $\begin{array}{ll}3 & 2 \\
3 & 8 \\
1 & 6 \\
2 & 7 \\
2 & 6 \\
1 & 4 \\
3 & 7 \\
2 & 5 \\
3 & 6\end{array}$ & 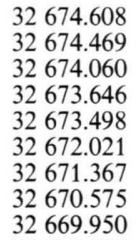 & $\begin{array}{r}-3.7 \\
8.7 \\
8.1 \\
14.5 \\
13.0 \\
8.9 \\
-9.6 \\
2.1 \\
3.6\end{array}$ \\
\hline $\begin{array}{llllll}6 & 2 & 4 & -6 & 1 & 5 \\
31 & 794.1401 & (17)\end{array}$ & $\begin{array}{ll}3 & 3 \\
1 & 6 \\
0 & 6 \\
3 & 9 \\
2 & 8 \\
1 & 7 \\
2 & 7 \\
3 & 8 \\
3 & 7 \\
2 & 6 \\
1 & 5 \\
3 & 6\end{array}$ & $\begin{array}{ll}3 & 3 \\
1 & 6 \\
2 & 6 \\
3 & 9 \\
3 & 8 \\
1 & 7 \\
2 & 7 \\
2 & 8 \\
3 & 7 \\
0 & 6 \\
1 & 5 \\
3 & 6\end{array}$ & 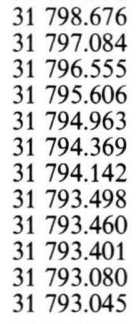 & $\begin{array}{r}-8.0 \\
6.3 \\
3.4 \\
3.4 \\
7.2 \\
2.4 \\
-3.5 \\
5.7 \\
7.4 \\
-7.1 \\
-1.5 \\
8.0\end{array}$ \\
\hline $\begin{array}{lllll}7 & 0 & 7-6 & 1 & 6 \\
28 & 035.0612 & (11)\end{array}$ & $\begin{array}{ll}3 & 8 \\
0 & 7 \\
3 & 7 \\
1 & 6 \\
3 & 9 \\
2 & 6 \\
2 & 8 \\
2 & 5 \\
2 & 9 \\
1 & 8 \\
3 & 6 \\
3 & 10 \\
3 & 5 \\
2 & 7 \\
1 & 7 \\
3 & 4\end{array}$ & $\begin{array}{ll}3 & 7 \\
0 & 6 \\
3 & 6 \\
1 & 5 \\
3 & 8 \\
2 & 5 \\
2 & 7 \\
2 & 4 \\
2 & 8 \\
1 & 7 \\
3 & 5 \\
3 & 9 \\
3 & 4 \\
2 & 6 \\
1 & 6 \\
3 & 3\end{array}$ & 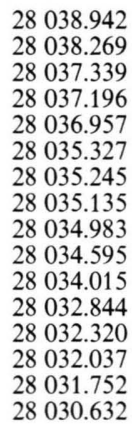 & $\begin{array}{r}0.1 \\
-0.2 \\
-0.4 \\
0.4 \\
1.7 \\
-2.2 \\
-1.2 \\
3.1 \\
1.9 \\
2.9 \\
1.6 \\
-0.2 \\
-2.8 \\
-2.0 \\
-2.6 \\
1.2\end{array}$ \\
\hline
\end{tabular}




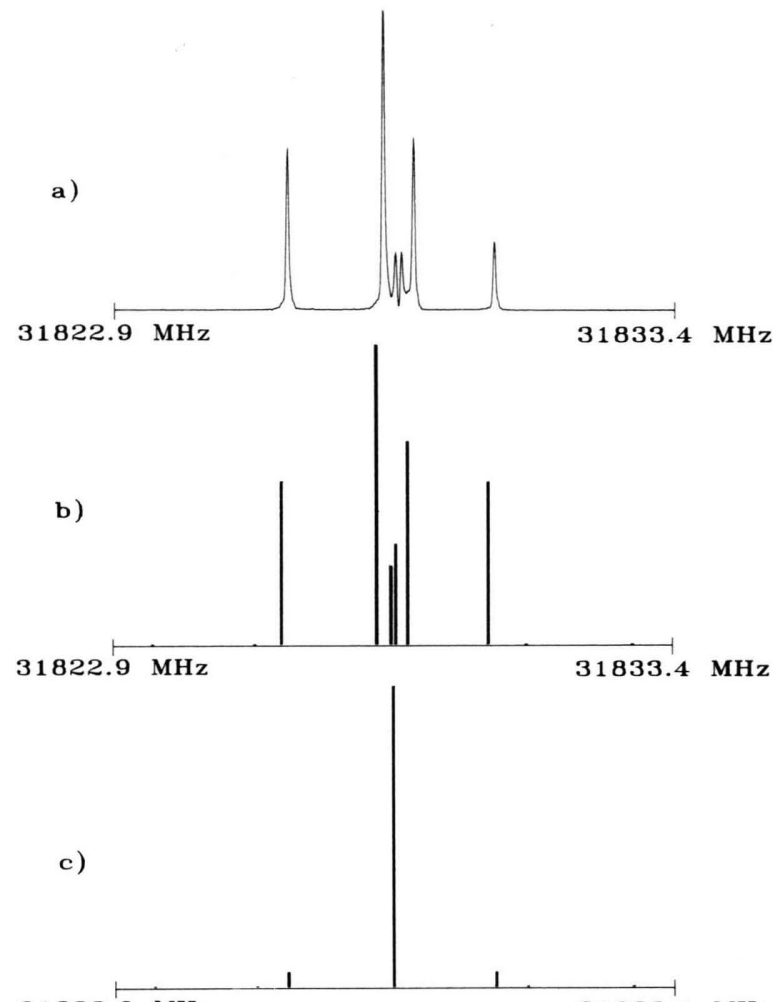

$31822.9 \mathrm{MHz}$

$31833.4 \mathrm{MHz}$

Fig. 1. Influence of second order quadrupole coupling effects in the rotational spectrum of ${ }^{35} \mathrm{Cl}_{2}$. - a) Experimental spectrum of $\mathrm{S}^{35} \mathrm{Cl}_{2}$ showing the transition $J^{\prime} K_{a}^{\prime} K_{c}^{\prime}-J K_{a} K_{c}=$ $6_{24}-6_{15}$. Polarizing frequencies $31825.0 \mathrm{MHz}$, pressure $0.3 \mathrm{~Pa}$ ( $2 \mathrm{mTorr}$ ), temperature $239 \mathrm{~K}, 1.1 \cdot 10^{6}$ averaging cycles, sample interval $20 \mathrm{~ns}, 1024$ data points supplemented with 3072 zeros prior to Fourier transformation. - b) Theoretical spectrum calculated with diagonalization of the Hamilton matrix. - c) Theoretical spectrum calculated with first order perturbation theory.

lected frequencies [9] for both the ${ }^{35} \mathrm{Cl},{ }^{35} \mathrm{Cl}$ and the ${ }^{35} \mathrm{Cl},{ }^{37} \mathrm{Cl}$ isotopomer are presented in Table 1 . A complete list is also given in [10].

\section{Analysis and Discussion}

An analysis of the hyperfine pattern with first order perturbation theory was not possible. The energy levels of some transitions were strongly influenced by matrix elements which depend on $\chi_{a b}$ and connect levels with similar energy. An example which shows the magnitude of the influence of these matrix elements is shown in the spectra of $\mathrm{S}^{35} \mathrm{Cl}_{2}$ given in Figure 1 . The energy difference between level $6_{24}$ and the
Table 2. Rotational-, centrifugal distortion- and quadrupole coupling constants of $\mathrm{S}^{35} \mathrm{Cl}_{2}$ and $\mathrm{S}^{35} \mathrm{Cl}^{37} \mathrm{Cl}$ in $\mathrm{MHz}$. Single standard error in brackets. $\theta_{z a}$ : angle between the $z$-principal axis of the quadrupole coupling tensor and the $a$-principal axes of the inertia tensor in degress. $N$ : number of lines in the fit, $\sigma$ : standard deviation of the fit in $\mathrm{kHz}$.

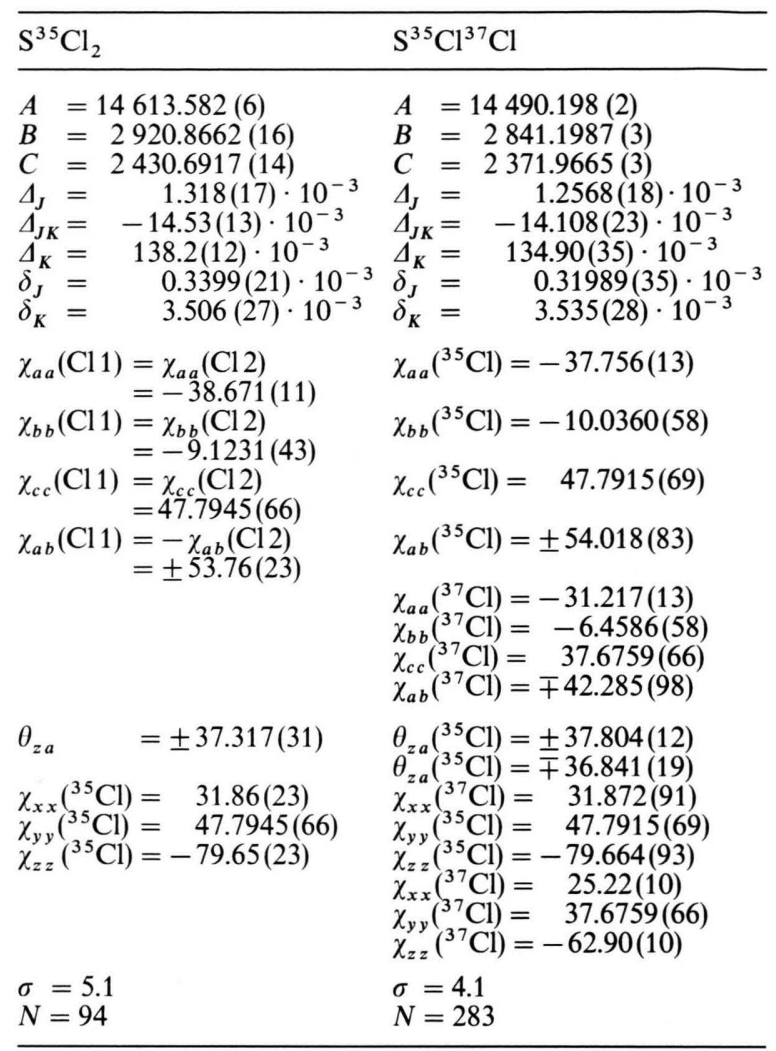

connected level $4_{32}$ is $62 \mathrm{MHz}$ and between $6_{15}$ and $5_{23}$ it is $726 \mathrm{MHz}$. In comparison to the prediction with first order treatment there are additional splittings and frequency shifts. In the given example transition some hyperfine components are shifted up to $390 \mathrm{kHz}$. The analysis was performed with direct diagonalization of the Hamiltonian matrix. The Hamiltonian is based on considerations in [11] and is set up in a coupled basis where the coupling scheme $I_{1}+I_{2}=I$, $I+J=F$ is used. Rotational and centrifugal distortion constants were determined with the program ZFAP 4 and held fixed during the fit of quadrupole coupling constants. Fit parameters were $\chi_{b b}, \chi_{c c}, \chi_{a b}$ and the hypothetical unsplit line frequencies. Due to some measured transitions with near degeneracy it was possible to determine the off diagonal elements $\chi_{a b}$ of the quadrupole coupling tensor with high accuracy. The determined coupling constants are given in Table 2 . 


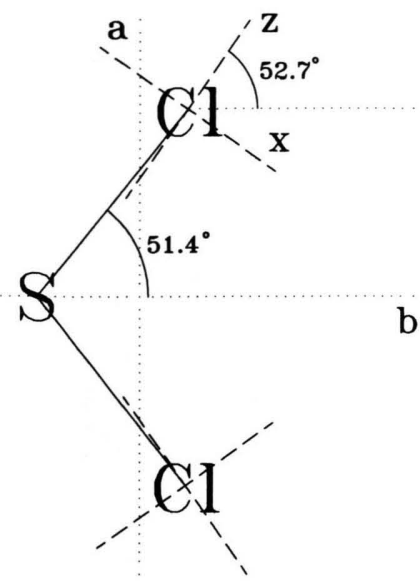

Fig. 2. Sulfur dichloride in its principal inertial axes system $(a, b)$. The $x$-and $z$-axes are principal axes of the quadrupole coupling tensor. The $z$-axis is tilted out of the $\mathrm{S}-\mathrm{Cl}$ internuclear axis by $1.3^{\circ}$. For better recognition this angle is drawn too large in the figure.

Since the axis perpendicular to the molecular plane is a principal axis of inertia and of the coupling tensor (c- and $y$-axis respectively), the knowledge of $\chi_{a b}$ allows the calculation of the angle $\theta_{z a}$ between the $z$-principal axis of the coupling tensor and the $a$-principal axes of the inertia tensor and the $\chi_{g g}, g=x, y, z$ coupling elements in the principal axes system of the inertia tensor. For the axis system see Figure 2. A comparison with the molecular structure [3] indicates that the $z$-axis of the coupling tensor is tilted $1.3^{\circ}$ with respect to the $\mathrm{S}-\mathrm{Cl}$ bond direction. The angle between both $z$-tensor axes is larger by $2.6^{\circ}$ than the $\mathrm{Cl}-\mathrm{S}-\mathrm{Cl}$ bond angle. A speculation that the principal axis of the coupling tensor in $\mathrm{SCl}_{2}$ might not coincide with the

[1] J. T. Murray, R. Williams, and T. L. Weatherly, Bull. Amer. Phys. Soc. 17, 575 (1972).

[2] J. T. Murray, W.A. Little, Q. Williams, and T. L. Weatherly, J. Chem. Phys. 65, 985 (1976).

[3] R. W. Davis and M. C. L. Gerry, J. Mol. Spectrosc. 65, 455 (1977).

[4] Chr. Keussen, N. Heineking, and H. Dreizler, Z. Naturforsch. 44a, 215 (1989).

[5] G. Bestmann, H. Dreizler, H. Mäder, and U. Andresen, Z. Naturforsch. 35a, 392 (1980).

[6] H. Ehrlichmann, J.-U. Grabow, H. Dreizler, N. Heineking, R. Schwarz, and U. Andresen, Z. Naturforsch. 44 a, 751 (1989).
$\mathrm{S}-\mathrm{Cl}$ bond axis was given by Murray et al. [2] in 1976 for the first time. They found a tilt-angle of $0.2^{\circ}$ between the principal axis of the coupling tensor and the $\mathrm{S}-\mathrm{Cl}$ bond axis. But this difference was within their experimental error of their measurements. The analysis of our MWFT data with direct diagonalization confirms the guess of these authors, but we found a larger tilt angle of $1.3^{\circ}$.

The electronic surrounding of the chlorine nuclei in both isotopomers can be expected to be the same and therefore for ${ }^{35} \mathrm{Cl}$ we expected the same coupling constants $\chi_{g g}(g=x, y, z)$ in the principal axes system of the coupling tensor for $\mathrm{S}^{35} \mathrm{Cl}_{2}$ and $\mathrm{S}^{35} \mathrm{Cl}^{37} \mathrm{Cl}$. The experimental result is given in Table 2 . A comparison with the structure indicates that in $\mathrm{S}^{35} \mathrm{Cl}^{37} \mathrm{Cl}$ the $z$ axis of the coupling tensor is also tilted $1.3^{\circ}$ with respect to the $\mathrm{S}-\mathrm{Cl}$ bond direction in the same way as in $\mathrm{S}^{35} \mathrm{Cl}_{2}$. This additionally supports the hypothesis of a bent bond. It seems interesting to us to look whether such effects also occur in other molecules. In 1,2-dichlorobenzene [12] there is a tilt angle of $1.3^{\circ}$ between the axis of the coupling tensor and the bond axis whereas in 1,3-dichlorobenzene [12] both axes coincide.

\section{Acknowledgement}

We thank the members of the Kiel group for help and discussions. Funds of the Deutsche Forschungsgemeinschaft, Fonds der Chemie, and the Land Schieswig-Hoistein are gratefuily acknowledged. The calculations were made at the computer center of the University of Kiel.

[7] I. Merke and H. Dreizler, Z. Naturforsch. 43a, 196 (1988).

[8] J. Haekel and H. Mäder, Z. Naturforsch. 43a, 203 (1988).

[9] A complete list of measured frequencies is available under TNA 26 from: Universitätsbibliothek der Universität Kiel, Westring 400, W-2300 Kiel 1, FRG.

[10] I. Merke, Dissertation Kiel 1992.

[11] W. Gordy and R. L. Cook, Microwave Molecular Spectra, J. Wiley, New York 1984, Chapter XV.

[12] I. Merke, Ch. Keussen, H. Dreizler, and M. Onda, Z. Naturforsch. 44a, 1273 (1990). 